\title{
Investigating the accelerated deterioration of flexible pavement using two-stage design analysis approach
}

\author{
Khaled A. Abaza $\cdot$ Suleiman A. Ashur
}

Received: 4 July 2010 /Accepted: 15 February 2011 / Published online: 7 May 2011

(C) The Author(s) 2011. This article is published with open access at SpringerLink.com

\begin{abstract}
Objective The accelerated deterioration of flexible pavement and its relation to design strength requirements is a major problem facing highway engineers. The goal of this research is to investigate a possible relationship between the accelerated pavement deterioration rates and pavement design strength using a two-stage design analysis approach. Approach Overview The approach in this study applies a two-stage solution to the three popular design methods of flexible pavement (i.e. California Department of Transportation (Caltrans) method, the American Association of State Highway and Transportation Officials (AASHTO) method, and the Asphalt Institute (AI) method) to yield pavement designs using stage load applications values specified for each investigated design load applications level. The resulting two-stage pavement designs are then used to obtain an indicator called the stage design strength ratio (percentage) defined as the ratio of the relative strength change to the design relative strength.

Results and Conclusions The sample results indicate that the stage design strength ratio is relatively low compared to the corresponding increase in load applications especially at advanced service times. This could be a major contributing factor to the accelerated deterioration of flexible pavement. Therefore, it is recommended to provide initially stronger pavement structures. This can be done by either designing
\end{abstract}

\section{K. A. Abaza}

Department of Civil Engineering, Birzeit University, P.O. Box 14,

Birzeit, West Bank, Palestine

e-mail:kabaza@birzeit.edu

\section{S. A. Ashur $(\triangle)$}

Department of Engineering, Civil Engineering Program, Indiana University-Purdue University Fort Wayne, Fort Wayne, IN 46805, USA

e-mail: ashurs@ipfw.edu flexible pavement for a longer design period than the typical 20 years suggested by most design methods or using a higher terminal present serviceability index as in the case of the AASHTO design method.

Keywords Flexible pavement · Pavement performance . Pavement design · Empirical design · Mechanistic design

\section{Introduction}

There are essentially three design approaches for flexible pavement: empirical, mechanistic, and mechanisticempirical [14]. The vast majority of design methods currently used by designers are either empirical or mechanistic-empirical. Recent research efforts have been focused towards the mechanistic-empirical approach which came about in response to the new proposed MechanisticEmpirical Pavement Design Guide (MEPDG) [20]. The new MEPDG represents a major advancement in pavement design; however, it is substantially more complex than the 1993 AASHTO empirical design guide. The new MEPDG has been under intensive testing and evaluation since it became available in 2004 [7, 8, 21]. It requires significantly more input data that may not be readily available to the designer. It also requires the calibration of several MEPDG predictive models for performance, traffic loading, and material characteristics. Therefore, the authors believe that design methods deploying the empirical approach will continue to be used in the design of flexible pavement especially in developing countries which generally lack the resources and technical expertise to use a mechanisticempirical approach such as the new MEPDG. However, certain design adjustments to the current flexible pavement design methods may be warranted based on earlier research findings $[1,2]$. 
Pavement performance is usually defined by a means of performance curve that depicts the trend between pavement condition rating and service time or accumulated load applications. Performance curves can be deterministically predicted from the AASHTO basic equation for the design of flexible pavement [3] or probabilistically predicted using the discrete-time Markov model [4, 9, 15]. However, actual performance curves can be developed using historical records of pavement distress. Figure 1 shows a typical pavement performance curve with accelerated pavement deterioration. The deterioration rates associated with the performance curve shown in Fig. 1 are progressively increasing until they reach high levels at the late stages of pavement service life $[9,13,17]$. In essence, pavement structures become relatively very weak in supporting the projected traffic loads during the late stages of the pavement service life. The outcome in this case is a high pavement life-cycle cost as added user cost becomes substantially higher in the absence of pavement maintenance and rehabilitation works $[1,12,18,19]$. Therefore, it can be concluded from the trend of a typical performance curve that currently used pavement design methods yield pavement designs that appear inadequate to withstand the progressive increase in load applications at advanced service times. This raises questions regarding the adequacy of the flexible pavement structures in supporting the anticipated future increases in traffic load applications. Some former studies have provided justifications for designing flexible pavement structures with higher strength than what is typically recommended by some current design methods $[1,2]$.

This paper attempts to investigate a possible relationship between the accelerated pavement deterioration rates and pavement design strength using a two-stage design analysis approach. The deployed approach applies a two-stage solution to the three popular design methods of flexible pavement to yield pavement designs using stage load applications values specified for each investigated design load applications level. The resulting two-stage pavement designs are then used to obtain an indicator called the stage design strength ratio (percentage) defined as the ratio of the

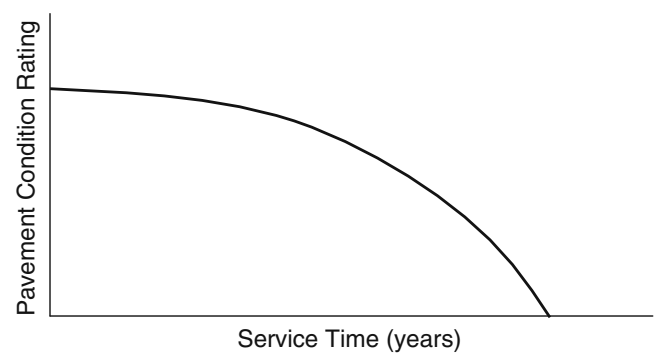

Fig. 1 Typical pavement performance curve relative strength change to the design relative strength. The relative strength change is the difference between the design relative strength associated with a design load applications level and stage relative strength associated with a stage load applications value that is less than or equal to the design load applications level. It basically provides a measure of strength difference resulting from two pavement designs obtained using two distinct loading conditions. Then, the derived values of stage design strength ratio are compared to the deployed stage load applications values.

The three investigated methods of flexible pavement design are the California Department of Transportation (Caltrans) method known as the California (Hveem) method, the American Association of State Highway and Transportation Officials (AASHTO) method, and the Asphalt Institute (AI) method. The Caltrans and AASHTO methods are two empirical methods of flexible pavement design and they deploy relative strength indicators as the main basis for the design of pavement structures. The Caltrans and AASHTO methods use gravel equivalent (GE) and structural number ( $\mathrm{SN}$ ) as the design relative strength indicators, respectively $[5,10]$. The AI method applies a mechanistic approach to obtain design solutions assuming linear elastic multi-layered pavement systems [6]. The AI method directly generates layer thicknesses that can be converted into an indicator of pavement relative strength. Therefore, the pavement relative strength indicators used in the proposed two-stage design analysis approach are the gravel equivalent, structural number, and layer thicknesses.

The Caltrans method is mostly used in California whereas the AASHTO and AI methods are used in the majority of states in the USA. Several studies have investigated pavement deterioration in the USA and Canada. A recent study [16] has investigated the local streets and roads in California and found based on the data that came from recognized pavement management systems that the statewide average pavement condition is deteriorating at a rate that is causing the California's local streets and roads system to reach a point of crisis. While inadequate design strength can contribute to the accelerated deterioration of pavements, other location related factors can also have a significant impact on pavement deterioration. In a Canadian study [11], it has been reported that climatic factors such as temperature, frost and thaw action, and moisture are a major cause of pavement deterioration. However, in locations such as California with moderate temperatures and low moistures, pavement deterioration rates are expected to be lower when considering similar pavement structures. Therefore, in California the accelerated deterioration of pavements can generally be attributed to factors such as traffic overloads and inadequate design strength. While recognizing the significance impact of the 
climatic factors on pavement deterioration, this paper will only investigate the influence of inadequate design strength on pavement performance.

\section{Two-stage design analysis approach}

A two-stage design analysis approach is used to investigate the accelerated deterioration of flexible pavement. A parameter called the "stage design strength ratio" is introduced as the main indicator to support the notion that the currently designed pavement structures lack the adequate strength required to withstand the progressive increase in load applications that takes place at advanced service times. Three very popular design methods of flexible pavement are used to determine the stage design strength ratio as presented in the subsequent subsections.

\subsection{Stage design strength ratio}

The investigation conducted in this paper to determine a relationship between the stage design strength ratio and the corresponding increase in load applications is based on using a relative strength indicator as presented in Eq. 1. The stage design strength ratio, $\mathrm{DS}(\mathrm{t})$, is simply related to the relative strength using a two-stage design analysis approach. The first-stage design requires the design relative strength associated with a design period of $(\mathrm{T})$ years whereas the second-stage design requires the stage relative strength considering a stage period of $(t)$ years that is less than or equal to the design period $(\mathrm{T})$. The stage design strength ratio, $\mathrm{DS}(\mathrm{t})$, according to Eq. 1, is defined as the ratio of the change in stage relative strength, $\Delta \mathrm{S}(\mathrm{t})$, to the design relative strength, $\mathrm{S}(\mathrm{T})$. The stage relative strength change, $\Delta \mathrm{S}(\mathrm{t})$, is defined as the difference between the design relative strength, $\mathrm{S}(\mathrm{T})$, and the stage relative strength, $\mathrm{S}(\mathrm{t})$. The use of design relative strength is consistent with the approach deployed by the two empirical methods for flexible pavement design, namely, the Caltrans and AASHTO design methods. Therefore, the relative strength can be represented by either the structural number ( $\mathrm{SN}$ ) or the gravel equivalent (GE) as will be presented later.

$\mathrm{DS}(\mathrm{t})=\frac{\Delta \mathrm{S}(\mathrm{t})}{\mathrm{S}(\mathrm{T})} \times 100 \%=\left(\frac{\mathrm{S}(\mathrm{T})-\mathrm{S}(\mathrm{t})}{\mathrm{S}(\mathrm{T})}\right) \times 100 \%$

where:

$$
\begin{aligned}
& \mathrm{S}(\mathrm{T})=\mathrm{S}(\mathrm{W}(\mathrm{T})) \\
& \mathrm{S}(\mathrm{t})=\mathrm{S}(\mathrm{W}(\mathrm{t})) \\
& 0 \leq \mathrm{W}(\mathrm{t}) \leq \mathrm{W}(\mathrm{T}) \\
& 0 \leq \mathrm{S}(\mathrm{t}) \leq \mathrm{S}(\mathrm{T}) \\
& 0 \leq \mathrm{t} \leq \mathrm{T}
\end{aligned}
$$

$\mathrm{DS}(\mathrm{t}) \quad$ stage design strength ratio in percentage;

$\Delta \mathrm{S}(\mathrm{t}) \quad$ stage relative strength change;

$\mathrm{S}(\mathrm{T}) \quad$ design relative strength associated with design load applications, $\mathrm{W}(\mathrm{T})$; and,

$\mathrm{S}(\mathrm{t}) \quad$ stage relative strength associated with stage load applications, $\mathrm{W}(\mathrm{t})$.

The stage design strength ratio as a percentage is determined using Eq. 1 based on the difference between the design relative strength, $\mathrm{S}(\mathrm{T})$, estimated for a given design load applications level, W(T), and the stage relative strength, $\mathrm{S}(\mathrm{t})$, associated with a specified stage load applications value, $\mathrm{W}(\mathrm{t})$, that is less than or equal to the design load applications level, $\mathrm{W}(\mathrm{T})$. The design relative strength, $S(T)$, is constant for a given design load applications level, $\mathrm{W}(\mathrm{T})$, while the stage relative strength, $\mathrm{S}(\mathrm{t})$, is variable depending on the value of the stage load applications, $\mathrm{W}(\mathrm{t})$. The $\mathrm{S}(\mathrm{T})$ represents the relative strength required for a design load applications level, W(T), corresponding to a design period of $(\mathrm{T})$ years. Whereas, the $\mathrm{S}(\mathrm{t})$ denotes the relative strength needed for a stage period of (t) years that is less than or equal to the design period $(\mathrm{T})$. The stage period $(\mathrm{t})$ starts from time zero and not from an intermediate time as typically done in a conventional two-stage design approach. Therefore, the $\mathrm{S}(\mathrm{t})$ takes on the value of zero when the stage period $(t)$ is set equal to zero which causes the stage design strength ratio, $\mathrm{DS}(\mathrm{t})$, to become equal to $100 \%$ according to Eq. 1 .

Figure 2 shows a typical inverse relationship between the stage relative strength, $S(t)$, and the stage design strength ratio, DS( $\mathrm{t})$. It can be noticed that the stage relative strength, $S(t)$, is shown to be smaller than the design relative strength, $\mathrm{S}(\mathrm{T})$, but they both have the same starting point which corresponds to a time of zero. Therefore, when the $S(t)$ value approaches zero, the change in stage relative strength, $\Delta \mathrm{S}(\mathrm{t})$, becomes equal to the design relative strength, $\mathrm{S}(\mathrm{T})$. This causes the stage design strength ratio, DS(t), to take on the value of $100 \%$ according to Eq. 1 . However, when the stage relative strength, $S(t)$, becomes

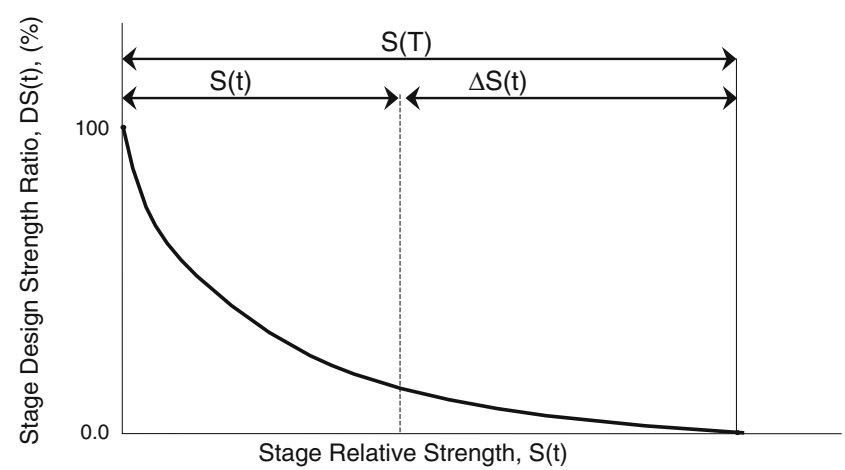

Fig. 2 Typical trend of stage relative strength versus stage design strength ratio 
equal to the design relative strength, $\mathrm{S}(\mathrm{T})$, then the stage relative strength ratio becomes equal to zero according to the Eq. 1. It is to be pointed out again that the outlined twostage design analysis approach is different from the conventional two-stage design approach wherein the first design is obtained using the first-stage load applications, $\mathrm{W}_{1}$, which equals to $\mathrm{W}(\mathrm{t})$ and the second design corresponds to the second-stage load applications, $\mathrm{W}_{2}$, that is equal to $\mathrm{W}(\mathrm{T})-\mathrm{W}(\mathrm{t})$. In essence, the $\mathrm{DS}(\mathrm{t})$ is determined from the design strengths associated with two pavement designs corresponding to two different design periods, namely, $t$ and $T$. In this sense, the DS( $(t)$ represents the percentage of additional strength required for a pavement design with $(\mathrm{T})$ years compared to the strength needed for a pavement design with $(t)$ years.

The stage load applications value, $\mathrm{W}(\mathrm{t})$, can be related to the design load applications level, W(T), using Eq. 2. The design load applications level is divided by the design traffic growth factor, $\mathrm{F}(\mathrm{T})$, to yield the estimated first-year load applications value. Then, the first-year load applications value is multiplied by the stage traffic growth factor, $F(t)$, to yield the projected stage load applications value, $\mathrm{W}(\mathrm{t})$, for a stage period of (t) years.

$\mathrm{W}(\mathrm{t})=\left(\frac{\mathrm{W}(\mathrm{T})}{\mathrm{F}(\mathrm{T})}\right) \times \mathrm{F}(\mathrm{t})$

where:

$\mathrm{W}(\mathrm{t}) \leq \mathrm{W}(\mathrm{T}), \mathrm{F}(\mathrm{t}) \leq \mathrm{F}(\mathrm{T})$, and $\mathrm{t} \leq \mathrm{T}$

$\mathrm{W}(\mathrm{t}) \quad$ stage load applications value associated with a stage period $(\mathrm{t})$ in years;

$\mathrm{W}(\mathrm{T})$ design load applications level associated with a design period $(\mathrm{T})$ in years;

$\mathrm{F}(\mathrm{T})$ design traffic growth factor associated with a design period $(\mathrm{T})$ in years; and,

$\mathrm{F}(\mathrm{t}) \quad$ stage traffic growth factor associated with a stage period $(t)$ in years.

The stage and design traffic growth factors can both be obtained from Eq. 3 recommended by the Asphalt Institute [6]. The annual traffic growth rate, $r$, in decimal form is required for using Eq. 3. The stage and design traffic growth factors are estimated from Eq. 3 using the stage and design periods, $\mathrm{t}$ and $\mathrm{T}$, respectively.

$F(t)=\frac{\left[(1+r)^{t}-1\right]}{r}$

The two main design parameters used in the design of flexible pavement are the $80 \mathrm{kN}$ equivalent single axle load (ESAL) applications and subgrade strength as represented by an appropriate strength indicator. The three investigated design methods mainly require these two parameters to obtain the required relative strength for a particular flexible pavement structure. Brief reviews of the three investigated design methods are provided in the subsequent subsections.

\subsection{California (Hveem) design method}

The California design method of flexible pavement is an empirical design method that uses a relative strength indicator known as the gravel equivalent, GE [10]. The gravel equivalent has been related to two main design parameters, namely, traffic loads and materials strength as presented in Eq. 4. The traffic loading condition is represented by the traffic index, TI, which is related to the design $80 \mathrm{kN}$ ESAL applications as provided in Eq. 4. Equation 4 represents the Caltrans basic design equation with minor modifications made to allow for the inclusion of the stage period $(t)$.

$\mathrm{GE}(\mathrm{t})=0.0032 \times \mathrm{TI}(\mathrm{t}) \times(100-\mathrm{R})$

where:

$\mathrm{TI}(\mathrm{t})=9.0 \times\left(\frac{\mathrm{W}(\mathrm{t})}{10^{6}}\right)^{0.119}$

GE(t) gravel equivalent associated with a stage period (t);

$\mathrm{TI}(\mathrm{t}) \quad$ traffic index associated with a stage load applications value, $\mathrm{W}(\mathrm{t})$; and,

$\mathrm{R}$ resistance value indicative of subgrade strength.

The stage design strength ratio as defined in Eq. 1 can be obtained using gravel equivalent as the relative strength indicator as indicated by Eq. 5a. The gravel equivalent as defined in Eq. 4 is substituted in Eq. 1, the stage load applications value, $\mathrm{W}(\mathrm{t})$, is replaced as presented in Eq. 2, and simplifications are then made to yield Eq. 5b, which can provide a direct solution to the stage design strength ratio.

$\mathrm{DS}(\mathrm{t})=\left(\frac{\mathrm{GE}(\mathrm{T})-\mathrm{GE}(\mathrm{t})}{\mathrm{GE}(\mathrm{T})}\right) \times 100 \%$

$\mathrm{DS}(\mathrm{t})=\left(1-\left(\frac{\mathrm{F}(\mathrm{t})}{\mathrm{F}(\mathrm{T})}\right)^{0.119}\right) \times 100 \%$

$\operatorname{DS}(t)=\left(1-\left(\frac{(1+r)^{t}-1}{(1+r)^{T}-1}\right)^{0.119}\right) \times 100 \%$

According to the Caltrans design method, Eq. 5b states that the stage design strength ratio is independent of design load applications and subgrade strength. It is only depen- 
dent on the stage and design traffic growth factors, $\mathrm{F}(\mathrm{t})$ and $\mathrm{F}(\mathrm{T})$, as obtained from Eq. 3. These two growth factors are further replaced by their corresponding values in terms of the annual traffic growth rate (r) and the time periods ( $t$ and T) as defined in Eq. 3 to yield Eq. 5c. Therefore, according to Eq. $5 \mathrm{c}$, the stage design strength ratio is only dependent on three factors, namely, (r), ( $\mathrm{t}$ ) and $(\mathrm{T})$, regardless of the values of any other design parameters.

\subsection{AASHTO design method}

The AASHTO method of flexible pavement design is another empirical design method that uses a relative strength indicator known as the structural number, SN. The structural number is derived from the AASHTO basic design equation based on design load applications, subgrade strength, and traffic and performance prediction parameters [5]. The design approach applies all design parameters to obtain a measure of the required relative strength through an index known as the structural number, SN. Equation 6 provides the AASHTO basic equation used in the design of flexible pavement with minor modifications made to allow for the inclusion of the stage period ( $\mathrm{t}$ ).

$$
\begin{aligned}
\log W(t)= & Z_{R} S_{o}+9.36 \log (S N(t)+1) \\
& +\frac{\log \left[\frac{\Delta P S I}{4.2-1.5}\right]}{0.40+\frac{1094}{(S N(t)+1)^{5.19}}}+2.32 \log \left(M_{R}\right)-8.27
\end{aligned}
$$

where:

W(t) stage $80 \mathrm{kN}$ ESAL applications associated with a stage period $(\mathrm{t})$ in years;

$Z_{R} \quad$ standard normal deviate for a specified reliability level;

$\mathrm{S}_{\mathrm{O}} \quad$ combined standard error of the traffic prediction and performance prediction;

$\Delta$ PSI difference between the initial or present serviceability index and the terminal serviceability index;

$\mathrm{SN}(\mathrm{t}) \quad$ stage structural number associated with a stage period (t); and,

$M_{R} \quad$ subgrade resilient modulus and must be in pound per square inch.

Once all design parameters are estimated, Eq. 6 is solved for the stage structural number, $\mathrm{SN}(\mathrm{t})$, based on the stage load applications value, $\mathrm{W}(\mathrm{t})$, by trial and error or consulting the equivalent AASHTO design chart [5]. The stage load applications value, W(t), for a specified stage period $(\mathrm{t})$ is obtained from Eq. 2 using the design load applications level, W(T), estimated from conducting appropriate traffic studies. The design structural number, $\mathrm{SN}(\mathrm{T})$, is also obtained from Eq. 6 using the design $80 \mathrm{kN}$ ESAL applications level, W(T). Then, the estimated stage and design structural numbers are used in Eq. 1 to obtain the stage design strength ratio as provided in Eq. 7.

$\mathrm{DS}(\mathrm{t})=\left(\frac{\mathrm{SN}(\mathrm{T})-\mathrm{SN}(\mathrm{t})}{\mathrm{SN}(\mathrm{T})}\right) \times 100 \%$

\subsection{Asphalt Institute design method}

The Asphalt Institute design method is mainly a mechanistic method that applies the linear elastic theory to obtain solutions for layered systems of flexible pavement structures. Experience, established theory, and test data are used to evaluate two specific stress-strain conditions. The design criteria are based on maximum allowable tensile strains at the bottom of the asphalt layer and maximum allowable vertical compressive strains at the top of the subgrade layer [6]. The design procedure determines the minimum thickness of the asphalt layer that will adequately withstand the stresses that develop for the two outlined strain criteria. Thickness design charts are provided for selected pavement structures consisting mainly of two and three layers' systems [6].

The two-layer system is a full-depth asphalt pavement. The three-layer system consists of a minimum asphalt layer thickness and a specified aggregate base thickness. The design parameters needed to consult a particular design chart are the design $80 \mathrm{kN}$ ESAL applications, subgrade strength as represented by the resilient modulus, and mean annual air temperature. The obtained layers' thicknesses can be converted into an equivalent relative strength indicator similar to the gravel equivalent and structural number using appropriate relative strength layers' coefficients as recommended by Caltrans and AASHTO design methods. However, if a full-depth asphalt pavement is used, then the thickness of the full-depth asphalt pavement can solely be used as an indicator of relative strength without the need to use a relative strength coefficient. Therefore, Eq. 8 is used to obtain the stage design strength ratio based on the thickness of full-depth asphalt pavement as obtained from the relevant Asphalt Institute design charts [6].

$\mathrm{DS}(\mathrm{t})=\left(\frac{\mathrm{D}(\mathrm{T})-\mathrm{D}(\mathrm{t})}{\mathrm{D}(\mathrm{T})}\right) \times 100 \%$

where:

$\mathrm{D}(\mathrm{T})$ full-depth asphalt pavement thickness for a design period of $(\mathrm{T})$ years, and

$D(t) \quad$ full-depth asphalt pavement thickness for a stage period of $(\mathrm{t})$ years.

The stage design strength ratio, as obtained from the three outlined flexible pavement design methods, will be investigated using variable design input parameters with results provided in the sample presentation section. 
Table 1 Sample stage $80 \mathrm{kN}$ ESAL applications values

\begin{tabular}{|c|c|c|c|c|c|}
\hline \multirow{3}{*}{$\begin{array}{l}\text { Stage period }(\mathrm{t}) \text {, } \\
\text { years }\end{array}$} & \multicolumn{5}{|c|}{ Stage $80 \mathrm{kN}$ ESAL Applications Value, W(t), $\left(\mathrm{x} 10^{6}\right)$} \\
\hline & \multicolumn{5}{|c|}{ Design $80 \mathrm{kN}$ ESAL Applications Level, W(T), $\left(\times 10^{6}\right)$} \\
\hline & 1.0 & 5.0 & 10.0 & 25.0 & 50.0 \\
\hline 0.0 & 0.0000 & 0.0000 & 0.0000 & 0.0000 & 0.0000 \\
\hline 0.5 & 0.0166 & 0.0831 & 0.1663 & 0.4156 & 0.8313 \\
\hline 1.0 & 0.0336 & 0.1679 & 0.3358 & 0.8395 & 1.6791 \\
\hline 2.0 & 0.0685 & 0.3425 & 0.6851 & 1.7127 & 3.4253 \\
\hline 4.0 & 0.1426 & 0.7130 & 1.4260 & 3.5651 & 7.1302 \\
\hline 6.0 & 0.2227 & 1.1137 & 2.2275 & 5.5687 & 11.1373 \\
\hline 8.0 & 0.3094 & 1.5471 & 3.0943 & 7.7357 & 15.4715 \\
\hline 10.0 & 0.4032 & 2.0159 & 4.0319 & 10.0796 & 20.1593 \\
\hline 12.0 & 0.5046 & 2.5230 & 5.0459 & 12.6148 & 25.2296 \\
\hline 14.0 & 0.6143 & 3.0714 & 6.1427 & 15.3569 & 30.7137 \\
\hline 16.0 & 0.7329 & 3.6645 & 7.3291 & 18.3226 & 36.6453 \\
\hline 18.0 & 0.8612 & 4.3061 & 8.6122 & 21.5304 & 43.0609 \\
\hline 20.0 & 1.0000 & 5.0000 & 10.0000 & 25.0000 & 50.0000 \\
\hline
\end{tabular}

\section{Sample results and discussion}

Sample results have been obtained for the stage design strength ratio that would support the suggestion that accelerated deterioration of flexible pavement could be attributed to a design inadequacy. The stage design strength ratio is determined for the three presented design methods using typical values for various design parameters. Also, the stage design strength ratio has been determined for five levels of design $80 \mathrm{kN}$ ESAL applications. The stage $80 \mathrm{kN}$ ESAL applications value, $\mathrm{W}(\mathrm{t})$, is determined for each design $80 \mathrm{kN}$ ESAL applications level, W(T), using variable stage period $(\mathrm{t})$ assuming $4 \%$ annual traffic growth rate (r) and 20 years design period (T). The stage load applications value is determined using Eqs. 2 and 3 with the pertaining results provided in Table 1. Also, Fig. 3 shows an equivalent graphical display of the same results. It is to be noted that for all investigated loading levels about $40 \%$

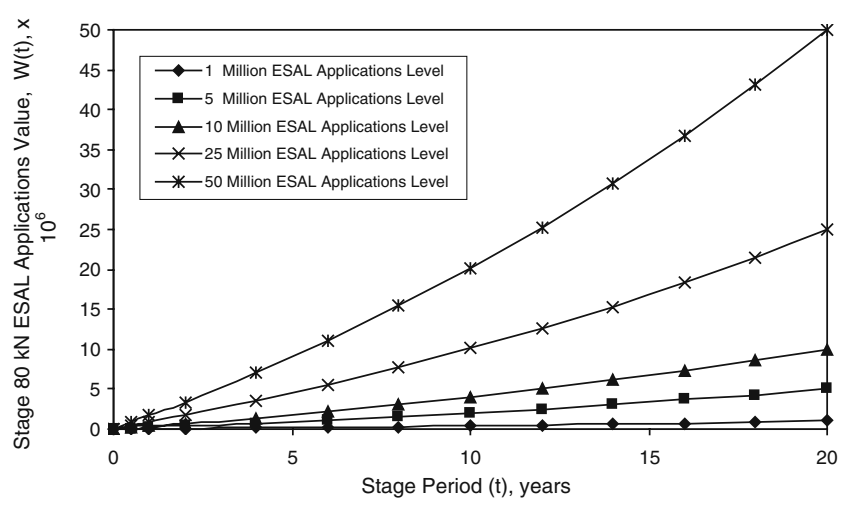

Fig. 3 Sample stage traffic load applications values of load applications takes place during the first half of the design period ( $\mathrm{t}=10$ years) with the remaining $60 \%$ occurs during the second half.

\subsection{Sample stage design strength ratio}

The stage design strength ratio is determined for the assumed loading levels using Caltrans design method with the results provided in Table 2. The subgrade strength as represented by the resistance value (R) is assumed to be 20 . Equation 5a is used to determine the stage design strength ratio as a percentage using the specified stage periods. Table 2 indicates that the stage design strength ratios are the same for all loading levels considering the same stage period. This has already been proven in Eq. $5 \mathrm{c}$ which states that the stage design strength ratio is independent of design load applications and subgrade strength. The important observation is being the progressive decrease in stage design strength ratio for the same design loading level. It reaches the value of only $10.24 \%$ at a stage period of 10 years, which represents the additional strength provided to account for about $60 \%$ of load applications to be generated during the second half of the design period. In other words, the difference in design strength resulting from a particular load applications level and $40 \%$ of that load level is only $10.24 \%$. The stage design strength ratio continues to decrease sharply at advanced stage periods resembling to a great extent the accelerated deterioration trend associated with a typical flexible pavement performance curve.

Similarly, the stage design strength ratio is determined for the two other design methods using the same loading levels. The assumed design input parameters according 
Table 2 Sample stage design strength ratio using Caltrans design method

\begin{tabular}{|c|c|c|c|c|c|c|}
\hline \multirow{3}{*}{$\begin{array}{l}\text { Stage period }(\mathrm{t}) \text {, } \\
\text { years }\end{array}$} & \multicolumn{5}{|c|}{ Stage Design Strength Ratio, DS(t), (\%) } & \\
\hline & \multicolumn{5}{|c|}{ Design 80 kN ESAL Applications Level, W(T), $\left(10^{6}\right)$} & \\
\hline & 1.0 & 5.0 & 10.0 & 25.0 & 50.0 & \\
\hline 0.0 & 100.00 & 100.00 & 100.00 & 100.00 & 100.00 & 100.00 \\
\hline 0.5 & 38.58 & 38.58 & 38.58 & 38.58 & 38.58 & 38.58 \\
\hline 1.0 & 33.23 & 33.23 & 33.23 & 33.23 & 33.23 & 33.23 \\
\hline 2.0 & 27.31 & 27.31 & 27.31 & 27.31 & 27.31 & 27.31 \\
\hline 4.0 & 20.69 & 20.69 & 20.69 & 20.69 & 20.69 & 20.69 \\
\hline 6.0 & 16.36 & 16.36 & 16.36 & 16.36 & 16.36 & 16.36 \\
\hline 8.0 & 13.03 & 13.03 & 13.03 & 13.03 & 13.03 & 13.03 \\
\hline 10.0 & 10.24 & 10.24 & 10.24 & 10.24 & 10.24 & 10.24 \\
\hline 12.0 & 7.82 & 7.82 & 7.82 & 7.82 & 7.82 & 7.82 \\
\hline 14.0 & 5.63 & 5.63 & 5.63 & 5.63 & 5.63 & 5.63 \\
\hline 16.0 & 3.63 & 3.63 & 3.63 & 3.63 & 3.63 & 3.63 \\
\hline 18.0 & 1.76 & 1.76 & 1.76 & 1.76 & 1.76 & 1.76 \\
\hline 20.0 & 0.00 & 0.00 & 0.00 & 0.00 & 0.00 & 0.00 \\
\hline
\end{tabular}

to the AASHTO method are: $\mathrm{M}_{\mathrm{R}}=70 \mathrm{MPa}(10,000 \mathrm{psi})$, $Z_{R}=-1.645$ for $95 \%$ reliability level, $S_{o}=0.35$, initial present serviceability index $(\mathrm{PSI})=4.5$, terminal $\mathrm{PSI}=2.0$. The assumed design input parameters according to the AI method are: $\mathrm{M}_{\mathrm{R}}=70 \mathrm{MPa}(10,000 \mathrm{psi})$, and $60^{\circ} \mathrm{F}$ mean annual air temperature. The resilient modulus value used in the two methods is the equivalent value for a resistance R-value of 20, used in the Caltrans method, as obtained from the correlation formula provided in Eq. 9.

$\mathrm{M}_{\mathrm{R}}(\mathrm{psi})=\mathrm{A}+\mathrm{B} \times(\mathrm{R}$ value $)$

Where coefficient A varies from 772 to 1155 and coefficient B varies from 369 to 555 with average coefficient values have been used in making the sample conversion [6].

Table 3 provides the sample stage design strength ratio as obtained from the AASHTO design method using Eqs. 6 and 7. The tabulated values are just a little higher than the corresponding ones obtained from the Caltrans method. Also, the tabulated values show some decline in magnitude as design loading level increases considering the same stage period, which seems to be contrary to what would be expected.

Table 4 provides similar results using the AI design method assuming a full-depth asphalt pavement obtained from consulting the applicable AI design chart [6] and then
Table 3 Sample stage design strength ratio using AASHTO design method

\begin{tabular}{|c|c|c|c|c|c|c|}
\hline \multirow{3}{*}{$\begin{array}{l}\text { Stage period }(\mathrm{t}) \text {, } \\
\text { years }\end{array}$} & \multicolumn{5}{|c|}{ Stage Design Strength Ratio, DS(t), (\%) } & \\
\hline & \multicolumn{5}{|c|}{ Design $80 \mathrm{kN}$ ESAL Applications Level, W(T), $\left(\times 10^{6}\right)$} & \\
\hline & 1.0 & 5.0 & 10.0 & 25.0 & 50.0 & \\
\hline 0.0 & 100.00 & 100.00 & 100.00 & 100.00 & 100.00 & 100.00 \\
\hline 0.5 & 47.93 & 45.71 & 44.91 & 43.95 & 43.26 & 45.15 \\
\hline 1.0 & 41.19 & 39.30 & 38.61 & 37.76 & 37.14 & 38.80 \\
\hline 2.0 & 33.79 & 32.26 & 31.68 & 30.96 & 30.42 & 31.82 \\
\hline 4.0 & 25.55 & 24.39 & 23.94 & 23.36 & 22.94 & 24.04 \\
\hline 6.0 & 20.19 & 19.27 & 18.90 & 18.43 & 18.09 & 18.98 \\
\hline 8.0 & 16.06 & 15.32 & 15.02 & 14.64 & 14.37 & 15.08 \\
\hline 10.0 & 12.63 & 12.04 & 11.80 & 11.50 & 11.23 & 11.85 \\
\hline 12.0 & 9.63 & 9.18 & 8.99 & 8.76 & 8.59 & 9.03 \\
\hline 14.0 & 6.94 & 6.61 & 6.47 & 6.30 & 6.18 & 6.50 \\
\hline 16.0 & 4.47 & 4.26 & 4.16 & 4.06 & 3.98 & 4.18 \\
\hline 18.0 & 2.17 & 2.06 & 2.02 & 1.96 & 1.93 & 2.03 \\
\hline 20.0 & 0.00 & 0.00 & 0.00 & 0.00 & 0.00 & 0.00 \\
\hline
\end{tabular}


Table 4 Sample stage design strength ratio using AI design method

\begin{tabular}{|c|c|c|c|c|c|c|}
\hline \multirow{3}{*}{$\begin{array}{l}\text { Stage period }(\mathrm{t}) \text {, } \\
\text { years }\end{array}$} & \multicolumn{5}{|c|}{ Stage Design Strength Ratio, DS(t) (\%) } & \\
\hline & \multicolumn{5}{|c|}{ Design $80 \mathrm{kN}$ ESAL Applications Level, W(T), $\left(\times 10^{6}\right)$} & \\
\hline & 1.0 & 5.0 & 10.0 & 25.0 & 50.0 & \\
\hline 0.0 & 100.00 & 100.00 & 100.00 & 100.00 & 100.00 & 100.00 \\
\hline 0.5 & 52.10 & 54.74 & 55.22 & 56.25 & 55.28 & 54.72 \\
\hline 1.0 & 49.10 & 48.28 & 49.63 & 49.69 & 48.33 & 49.01 \\
\hline 2.0 & 40.12 & 41.81 & 42.16 & 41.88 & 40.56 & 41.30 \\
\hline 4.0 & 29.94 & 32.33 & 32.84 & 32.50 & 30.28 & 31.58 \\
\hline 6.0 & 24.55 & 26.29 & 26.12 & 26.25 & 24.72 & 25.59 \\
\hline 8.0 & 19.76 & 20.69 & 20.90 & 20.00 & 19.17 & 20.10 \\
\hline 10.0 & 16.17 & 16.38 & 17.54 & 16.25 & 14.72 & 16.21 \\
\hline 12.0 & 11.98 & 12.50 & 13.43 & 12.50 & 11.11 & 12.30 \\
\hline 14.0 & 8.38 & 8.62 & 10.07 & 8.75 & 7.50 & 8.66 \\
\hline 16.0 & 5.39 & 6.03 & 5.60 & 5.62 & 5.00 & 5.53 \\
\hline 18.0 & 2.99 & 3.88 & 2.98 & 2.50 & 2.50 & 2.97 \\
\hline 20.0 & 0.00 & 0.00 & 0.00 & 0.00 & 0.00 & 0.00 \\
\hline
\end{tabular}

applying Eq. 8. The tabulated values are generally higher than the corresponding ones obtained from the two other design methods. The stage design strength ratio reaches an average value of $16.21 \%$ at a stage period of 10 years. The AI tabulated values seem to be independent of design loading level although they show some unclear pattern of variation, which could be attributed to minor errors related to scaling pavement thickness off the relevant design chart. It can generally be concluded based on the sample stage design strength ratios obtained from the three investigated design methods that very modest additional strength is provided for substantial increases in design load applications.

The stage design strength ratio as obtained from the three investigated design methods for the 10 millions load applications level is shown in Fig. 4 as a function of stage load applications. Also, the average stage design strength ratio as obtained from the three design methods as a

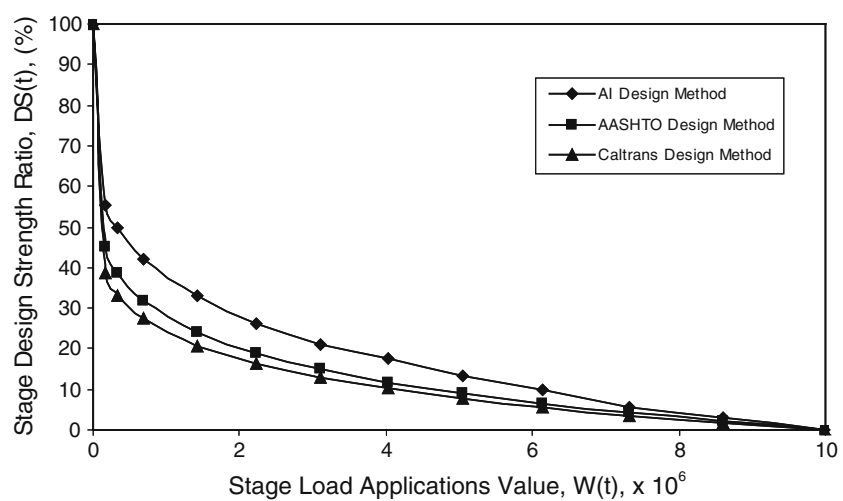

Fig. 4 Stage design strength ratio associated with 10 millions load applications level function of stage period is shown in Fig. 5. The curves depicted in Figs. 4 and 5 have similar trends with a slope that starts very steep due to minimum design strength requirements and then progressively decreases until it nearly becomes flat. The curves depicted in Figs. 4 and 5 very much resemble the general trend shown in Fig. 2. Figures 4 and 5 both show that the Asphalt Institute design method has consistently provided slightly higher stage design strength ratios compared to the corresponding ones obtained from the Caltrans and AASHTO design methods.

\subsection{Impact of design period on stage design strength ratio}

The impact of design period $(\mathrm{T})$ on stage design strength ratio, $\mathrm{DS}(\mathrm{t}, \mathrm{T})$, is investigated using the Caltrans design method. The stage design strength ratios have been

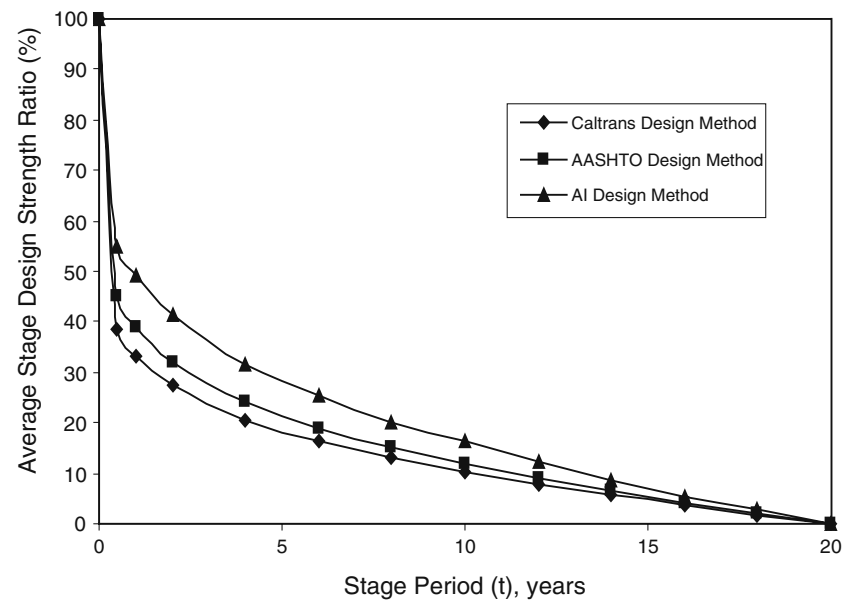

Fig. 5 Sample average stage design strength ratio 
computed using two additional design periods, namely, 25 and 30 years with results provided in Table 5 . These results are compared against the corresponding ones obtained using 20 years design period. The percentage of increase in the value of stage design strength ratio, $\Delta \mathrm{DS}(\mathrm{t}, \mathrm{T})$, is determined according to Eq. 10. It can be noticed from Table 5 that the increase in the design period, compared to 20 years, has resulted in an exponential increase in the value of $\Delta \mathrm{DS}(\mathrm{t}, \mathrm{T})$. This exponential increase in the stage design strength ratio can certainly help improving the longterm performance of pavements.

$\Delta \mathrm{DS}(\mathrm{t}, \mathrm{T})=\frac{\mathrm{DS}(\mathrm{t}, \mathrm{T})-\mathrm{DS}(\mathrm{t}, 20)}{\mathrm{DS}(\mathrm{t}, 20)} \quad$ where $: \mathrm{T}=25$ or 30 years

In addition, the average stage design strength ratios are computed for the 20,25 and 30 years design periods and found to be $21.41 \%, 24.48 \%$ and $27.11 \%$, respectively, considering only the first twenty years of the pavement life. This corresponds to an increase in the average stage design strength ratio amounting to $14.34 \%$ and $26.62 \%$ when comparing the 25 and 30 years design periods against the 20 years design period, respectively. Therefore, the use of a longer design period can help lessening the accelerated deterioration of pavements.

\subsection{Impact of terminal PSI on stage design strength ratio}

There is a major difference between the AASHTO design method and the other design methods in relation to the expected pavement performance. The AASHTO design method allows the designer to control pavement performance by specifying a terminal PSI value. The AASHTO recommended values for terminal PSI are 2.5 and 2.0 for major and minor roads, respectively. Table 6 provides sample stage design strength ratios, DS(10), calculated for a stage period of 10 years and variable terminal PSI values using two design load applications levels. It can be concluded that minor improvement in the stage design strength ratio has occurred in the case of five millions load applications level and no improvement in the case of fifty millions load applications level despite the major variation in the terminal PSI value. However, increasing the terminal PSI value has resulted in a major improvement in the pavement relative strength as indicated by the design structural number, $\mathrm{SN}(20)$. Therefore, it is recommended to use terminal PSI values higher than the current ones recommended by AASHTO.

\subsection{Sample mechanistic results}

A mechanistic verification of the impact of design load on stage design strength ratio can be performed using an analysis of layered pavement systems. One and two-layered elastic systems are considered using maximum surface deflection as the criterion for design basis. The basic equation that relates maximum surface deflection to the static wheel load for a one-layered system is provided in Eq. 11a. The corresponding deflection factor $\left(\mathrm{F}_{1}\right)$ is defined using Eq. 11b, which is solved for the pavement design
Table 5 Impact of design period $(\mathrm{T})$ on stage design strength ratio using Caltrans design method

\begin{tabular}{|c|c|c|c|c|c|c|}
\hline \multirow{2}{*}{$\begin{array}{l}\text { Table } 5 \text { Impact of design } \\
\text { period }(\mathrm{T}) \text { on stage design } \\
\text { strength ratio using Caltrans } \\
\text { design method }\end{array}$} & \multirow{2}{*}{$\begin{array}{l}\text { Stage period }(t) \text {, } \\
\text { years }\end{array}$} & \multicolumn{3}{|c|}{$\mathrm{DS}(\mathrm{t}, \mathrm{T}),(\%)$} & \multicolumn{2}{|c|}{$\Delta \mathrm{DS}(\mathrm{t}, \mathrm{T}),(\%)$} \\
\hline & & $\mathrm{DS}(\mathrm{t}, 30)$ & $\mathrm{DS}(\mathrm{t}, 25)$ & $\mathrm{DS}(\mathrm{t}, 20)$ & $\Delta \mathrm{DS}(\mathrm{t}, 30)$ & $\Delta \mathrm{DS}(\mathrm{t}, 25)$ \\
\hline & 0.0 & 100.00 & 100.00 & 100.00 & 0 & 0 \\
\hline & 0.5 & 43.04 & 40.99 & 38.58 & 11.56 & 6.25 \\
\hline & 1.0 & 38.07 & 35.84 & 33.23 & 14.56 & 7.85 \\
\hline & 2.0 & 32.59 & 30.16 & 27.31 & 19.33 & 10.44 \\
\hline & 4.0 & 26.44 & 23.79 & 20.69 & 27.79 & 14.98 \\
\hline & 6.0 & 22.43 & 19.64 & 16.36 & 37.10 & 20.05 \\
\hline & 8.0 & 19.34 & 16.43 & 13.03 & 48.43 & 26.09 \\
\hline & 10.0 & 16.76 & 13.76 & 10.24 & 63.67 & 34.34 \\
\hline & 12.0 & 14.51 & 11.42 & 7.82 & 85.55 & 46.04 \\
\hline & 14.0 & 12.48 & 9.33 & 5.63 & 121.67 & 65.72 \\
\hline & 16.0 & 10.62 & 7.40 & 3.63 & 192.56 & 103.86 \\
\hline & 18.0 & 8.89 & 5.61 & 1.76 & 405.11 & 218.75 \\
\hline & 20.0 & 7.26 & 3.91 & 0.00 & _@ & - \\
\hline & 24.0 & 4.21 & 0.75 & - & - & - \\
\hline & 25.0 & 3.48 & 0.00 & - & - & - \\
\hline & 28.0 & 1.36 & - & - & - & - \\
\hline (a) The value is not annlicchble & 30.0 & 0.00 & - & - & - & - \\
\hline
\end{tabular}


Table 6 Impact of terminal PSI value on stage design strength ratio

\begin{tabular}{|c|c|c|c|c|c|c|c|}
\hline \multicolumn{4}{|c|}{$\mathrm{W}(\mathrm{T})=5.0 \times 10^{6}$} & \multicolumn{4}{|c|}{$\mathrm{W}(\mathrm{T})=50.0 \times 10^{6}$} \\
\hline Terminal PSI & $\mathrm{SN}(20)$ & $\mathrm{SN}(10)$ & DS(10) & Terminal PSI & $\mathrm{SN}(20)$ & $\mathrm{SN}(10)$ & $\mathrm{DS}(10)$ \\
\hline 4.0 & 6.00 & 5.11 & 14.83 & 4.0 & 8.26 & 7.33 & 11.26 \\
\hline 3.5 & 4.71 & 3.96 & 15.92 & 3.5 & 6.65 & 5.86 & 11.88 \\
\hline 3.0 & 4.17 & 3.58 & 14.15 & 3.0 & 5.87 & 5.16 & 12.10 \\
\hline $2.5^{\mathrm{a}}$ & 3.89 & 3.39 & 12.85 & $2.5^{\mathrm{a}}$ & 5.39 & 4.76 & 11.69 \\
\hline $2.0^{\mathrm{a}}$ & 3.72 & 3.27 & 12.04 & $2.0^{\mathrm{a}}$ & 5.07 & 4.50 & 11.23 \\
\hline 1.5 & 3.61 & 3.19 & 11.63 & 1.5 & 4.84 & 4.31 & 10.95 \\
\hline
\end{tabular}

thickness (h) to yield Eq. 11c. The deflection factor is numerically obtained from Eq. 11a based on maximum allowable surface deflection $(\Delta)$, wheel load $(\mathrm{P})$, contact tire pressure $(\rho)$, and subgrade elasticity modulus $(\mathrm{E})$. Then, the required total pavement thickness (h) can be determined from Eq. 11c.

$\Delta=\frac{\rho a}{E} F_{1}$, where a $=\sqrt{\frac{P}{\pi \rho}}$

$F_{1}=\frac{1.5}{\left[1+(h / a)^{2}\right]^{1 / 2}}$

$h=\sqrt{a^{2}\left(\left(1.5 / F_{1}\right)^{2}-1\right)}$

The basic deflection equation used in the design of twolayered pavement system is presented in Eq. 12. It is essentially similar to Eq. 11a except that the corresponding deflection factor $\left(\mathrm{F}_{2}\right)$ is related to the pavement design thickness ( $h$ ) and modular ratio $\left(\mathrm{E}_{2} / \mathrm{E}_{1}\right)$ using a design chart. The pavement thickness in a two-layered system is equivalent to a full-depth asphalt pavement with $\left(\mathrm{E}_{1}\right)$ modulus value.

$\Delta=\frac{1.5 \rho a}{E_{2}} F_{2}$

where $\mathrm{a}=\sqrt{\frac{P}{\pi \rho}}$ and $F_{2}=f\left(h / a, E_{2} / E_{1}\right)$
The deflection factor is first obtained from Eq. 12 based on maximum allowable surface deflection $(\Delta)$, wheel load $(P)$, contact tire pressure $(\rho)$, and subgrade modulus $\left(E_{2}\right)$. The required pavement thickness (in radii) is then determined by consulting the relevant design chart using the deflection factor and modular ratio $\left(\mathrm{E}_{2} / \mathrm{E}_{1}\right)$ as the main design parameters [14, 22]. English units are required for using Eqs. 11 and 12.

Sample mechanistic results are provided in Table 7 using $0.51 \mathrm{~mm}$ (0.02 inches) maximum allowable surface deflection, $70 \mathrm{MPa}$ (10,000 psi) subgrade modulus value, $0.56 \mathrm{MPa}(80 \mathrm{psi})$ contact tire pressure, and 1/50 modular ratio. The wheel load is varied over the range of 26.66$53.33 \mathrm{kN}$ (6-12 kips) with the corresponding pavement thicknesses from the one and two-layered systems are provided as $h_{1}$ and $h_{2}$, respectively. The estimated pavement design thickness has ranged from 34.34 to $70.59 \mathrm{~cm}$ (13.52-27.79 in.) as obtained from the one-layered system and $9.94-22.45 \mathrm{~cm}$ (3.91-8.84 in.) as obtained from the two-layered system. The results indicate that as the magnitude of the wheel load is increased, the required pavement thickness has increased in the same proportion. While recognizing the differences between the static and dynamic problems, it seems that the investigated Caltrans, AASHTO, and AI design methods provide a little additional strength for substantial increases in design load applications. It is by no means intended to suggest that there should be a linear relationship between load applications and stage design strength ratio, but would rather like to indicate that the investigated design methods do not seem to provide adequate strength to meet the progressive
Table 7 Sample mechanistic results using one and twolayered pavement systems (a) Kips \# Inches

\begin{tabular}{lllllr}
\hline $\mathrm{P}(\mathrm{kN})$ & $\mathrm{a}(\mathrm{cm})$ & $\mathrm{F}_{1}$ & $\mathrm{~h}_{1}(\mathrm{~cm})$ & $\mathrm{F}_{2}$ & $\mathrm{~h}_{2}(\mathrm{~cm})$ \\
\hline $26.66\left(6^{@}\right)$ & $12.42\left(4.89^{\#}\right)$ & 0.51 & $34.34\left(13.52^{\#}\right)$ & 0.34 & $9.94\left(3.91^{\#}\right)$ \\
$31.11(7)$ & $13.41(5.28)$ & 0.47 & $40.36(15.89)$ & 0.32 & $11.80(4.65)$ \\
$35.55(8)$ & $14.33(5.64)$ & 0.44 & $46.33(18.24)$ & 0.30 & $13.75(5.41)$ \\
$40.00(9)$ & $15.19(5.98)$ & 0.42 & $52.35(20.61)$ & 0.28 & $15.95(6.28)$ \\
$44.44(10)$ & $16.03(6.31)$ & 0.40 & $58.55(23.05)$ & 0.26 & $18.74(7.38)$ \\
$48.88(11)$ & $16.81(6.62)$ & 0.38 & $64.57(25.42)$ & 0.25 & $20.68(8.14)$ \\
$53.33(12)$ & $17.55(6.91)$ & 0.36 & $70.59(27.79)$ & 0.24 & $22.45(8.84)$ \\
\hline
\end{tabular}


increase in load applications that takes place at advanced service times.

\section{Conclusions and recommendations}

This paper has merely intended to focus the light on a possible cause of a major problem facing highway engineers that is the accelerated deterioration of flexible pavement and its relation to design strength requirements. Sample stage design strength ratio results have been presented using the three most popular design methods of flexible pavement. The Asphalt Institute design method has provided the highest stage design strength ratios when compared to the corresponding results obtained from the Caltrans and AASHTO design methods. The stage design strength ratios obtained at a stage period of 10 years according to Caltrans, AASHTO, and AI methods are only about 10,12 , and $16 \%$, respectively, which represent the additional strength provided to account for $60 \%$ of load applications expected to take place during the second half of design life. The low values of stage design strength ratio associated with advanced stage periods seem to support the claim that the accelerated deterioration of flexible pavement in the absence of rehabilitation work could be generally attributed to a design inadequacy.

The above claim is also supported by two well known facts. The first fact is derived from the typical performance trend of flexible pavement as depicted in Fig. 1. It is well documented that pavement performance is associated with successively increasing deterioration rates starting around the middle age of the pavement service life. The second fact is that pavement rehabilitation is explicitly recommended by some design methods such as the AASHTO method which requires rehabilitation action once the pavement reaches its terminal serviceability as defined by the terminal present serviceability index. Also, the general practice adopted by most highway agencies in developed countries is to schedule major rehabilitation remedies around the middle age of the pavement service life. These two facts along with the generally recommended rehabilitation practice implicitly acknowledge that the designed flexible pavement structures are inadequate to perform satisfactorily over the entire design period. This provides a solid support for the notion that the designed pavement structures are inadequate to meet the progressive increase in load applications that takes place at advanced service times.

Unfortunately, developing countries using the investigated design methods are confronted with scarce financial resources and cannot implement timely needed rehabilitation works. Therefore, the anticipated outcome is severely deteriorated pavements with a high added user cost. The recommendation in this case is to provide initially stronger pavement structures. This can be done by either designing flexible pavement for a longer design period than the typical 20 years suggested by most design methods or using a higher terminal present serviceability index as in the case of the AASHTO design method. Therefore, it is recommended that developing countries consider providing pavement structures that are slightly stronger compared to what can be currently obtained from the three investigated design methods. Former studies have provided justifications for constructing flexible pavements with higher strength than what is currently recommended by the AASHTO design method $[1,2]$. In particular, it has been recommended that higher terminal PSI values be used in the AASHTO design method compared to the currently recommended values.

Open Access This article is distributed under the terms of the Creative Commons Attribution License which permits any use, distribution and reproduction in any medium, provided the original author(s) and source are credited.

\section{References}

1. Abaza K (2002) An optimum flexible pavement life-cycle analysis model. ASCE J Transp Eng 128(6):542-549

2. Abaza K, Abu-Eisheh S (2003) An optimum design approach for flexible pavements. Int J Pavement Eng 4(1):1-11

3. Abaza K (2004) Deterministic performance prediction model for rehabilitation and management of flexible pavement. Int $\mathrm{J}$ Pavement Eng 5(2):111-121

4. Abaza K, Murad M (2009) Prediction of flexible pavement remaining strength and overlay design thickness using stochastic modelling. Transportation Research Record 2094, TRB, Washington, D.C., pp. 62-70

5. American Association of State Highway and Transportation Officials, AASHTO (1993) AASHTO guide for design of pavement structures. Washington, D.C.

6. Asphalt Institute, AI (1999) Thickness design-asphalt pavements for highways and streets, manual series no. 1, 9th edition, Lexington, KY

7. Banerjee A, Aguiar-Moya J, Prozzi J (2009) Texas experience using LTPP for calibration of the MEPDG permanent deformation models. Transportation Research Record 2094, TRB, Washington, D.C., pp. 12-20

8. Bari J, Witczak M (2007) New predictive models for the viscosity and complex shear modulus of asphalt binders for use with the mechanistic-empirical pavement design guide. Transportation Research Record 2001, TRB, Washington, D.C., pp. 9-19

9. Butt A, Shahin M, Feighan J, Carpenter S (1987) Pavement performance prediction model using the Markov Process. Transportation Research Record 1123, TRB, National Research Council, Washington, D.C., pp. 12-19

10. California Department of Transportation, Caltrans (2008) Highway Design Manual (HDM), 6th edition. Sacramento, CA

11. Dore G, Drouin P, Desrochers P, Ullidtz P (2006) Estimation of the relationships of flexible pavement deterioration to traffic and weather in Canada. Proceedings of the 10th International Conference on Asphalt Pavements, International Society for Asphalt Pavements, August 12-17, Quebec City, Canada

12. Federal Highway Administration, FHWA (1994) Life-cycle cost analysis summary of proceedings, life- cycle cost symposium, 
searching for solutions. A policy discussion series, no.12, FHWA, Washington, D.C.

13. George K, Rajagopal A, Lim L (1989) "Models for predicting pavement deterioration", Transportation Research Record 1215, TRB. National Research Council, Washington, D.C., pp 1-7

14. Huang Y (2004) Pavement analysis and design, second edition. Pearson/Prentice Hall, Upper Saddle River

15. Li N, Xie W, Haas R (1996) Reliability-based processing of Markov Chains for modeling pavement network deterioration. Transportation Research Record 1524, TRB, Washington, D.C., pp. 203-213

16. Nichols Consulting Engineers, Chtd. (2009) California Statewide Local Streets and Roads Needs Assessment. Final Report, October 20, Pt. Richmond, CA

17. Peterson D (1987) NCHRP synthesis of highway practice, report 135: pavement management practices. Transportation Research Board, National Research Council, Washington, D.C.
18. Shahin M, Stock C, Beckberger L (1994) Comparing pavement performance and its effect on maintenance and rehabilitation cost. Proceedings of the Third International Conference on Managing Pavement, Transportation Research Board, Washington, D.C., Vol. 1, pp. 237-245

19. Sheflin M (1983) Your choice: bad roads at high cost or good roads at low cost. Special Forum Report, Paving Forum

20. Transportation Research Board, TRB (2004) Guide for mechanistic-empirical design of new and rehabilitated pavement structures, Final Report, National Cooperative Highway Research Program, National Research Council, Washington, D.C.

21. Wang K, Li Q, Hall K, Nguyen V, Gong W, Hou Z (2008) Database Support for the New Mechanistic-Empirical Pavement Design Guide (MEPDG), Transportation Research Record 2087, TRB, Washington, D.C., pp. 109-119

22. Yoder E, Witczak M (1975) Principles of pavement design, Second edition. John Wiley and Sons, Inc 